\title{
GIS-technology and data of earth remote sensing to identify and predict ravine erosion development
}

\author{
Almaz Sabirzyanov ${ }^{1, *}$, Mikhail Panasyuk ${ }^{2}$, Nikolai Trofimov ${ }^{1}$ and Svetlana Sochneva ${ }^{1}$ \\ ${ }^{1}$ Kazan State Agrarian University, Kazan 420015, Republic of Tatarstan, Russia \\ ${ }^{2}$ Kazan Federal University, Kazan 420008, Republic of Tatarstan, Russia
}

\begin{abstract}
This article discusses the study of the process of ravine erosion using geoinformation technologies and Earth remote sensing data. Ravine erosion, which develops on the territory of the Verkhneuslonsky municipal region of the Republic of Tatarstan, is considered as a multifactorial process. The possibility of using freely available data to study the factors affecting ravine erosion is evaluated. It is shown that in modern conditions of increased anthropogenic environmental impact, especially in areas heavily divided by ravines, the use of GIS technology is sufficient in order to monitor and quickly respond to negative erosion processes occurring on agricultural lands.
\end{abstract}

\section{Introduction}

At the beginning of the 20th century, the process and phenomenon of ravine erosion were studied using topographic maps and aerial photographs. At this time, ravines were counted, their length was measured, the number of ravines per unit area and their area was calculated, which allowed researchers concluding about their constant growth. Manual measurements were laborious and took time for researchers. However, the emergence and implementation of GIS technologies greatly simplify such tasks as creating terrain models, calculating the slope and curvature of slope surfaces destroyed by erosion [1,2].

\section{Place and conditions of research}

The Verkhneuslonsky municipal district of the Republic of Tatarstan is located in the north-eastern part of the Volga Upland between the lower reaches of the Sviyaga and Volga (Fig. 1). The climate of the Verkhneuslonsky municipal region of the Republic of Tatarstan is temperate. This area is characterized by the transition of soil and plant zones from forest to the steppe. The soil cover is clayey. The relief is mainly wavy-flat, with cliffs and river valleys of the Sviyaga and Volga systems, numerous beams and ravines. Of the minerals, limestones, clays, dolomites, sands and sandstones are found $[3,4]$.

The most common absolute heights are from 100 to $200 \mathrm{~m}$. The highest point is $225.1 \mathrm{~m}$, which is located on the watershed of the Volga and Sulitsa rivers. The smallest maxima are located along the Volga ridge, and it is $53 \mathrm{~m}$. The relative excesses vary from 97 to $127 \mathrm{~m}$. The watershed of the Volga and Sulitsy belongs to the eastern part of the region. A significant dissection of the surface characterizes it along the valleys of small rivers, ravines, which are much smaller than in the western part $[5,6]$.

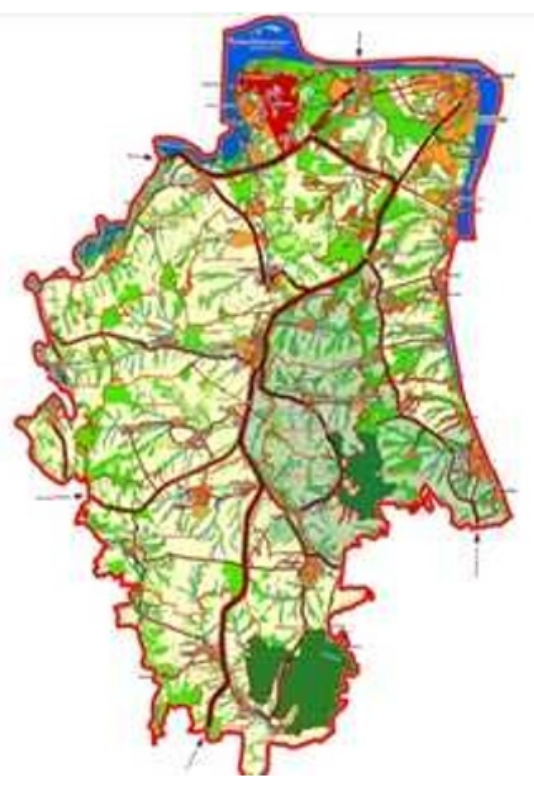

Fig. 1. Verkhneuslonsky municipal district of the Republic of Tatarstan (map-scheme)

Figure 2 shows fragments of a map of the expositions and slopes of the relief of the Verkhneuslonsky district. The watershed faces the Volga valley with high steep slopes with angles of up to 65 degrees [7]. The plakar surfaces and the water surface of the Kuibyshev reservoir correspond to zero slope values. Comparing the map of the slopes and the satellite image shows the network of ravines differs in medium and high values of slopes. The exposure map has an interval colour scale corresponding to the main points and a flat surface.

* Corresponding author: sabiralmaz@mail.ru 
The wind rose shown in Figure 3 illustrates the uniform distribution of topography across exposures. Of course, when studying expositions at the basic level, an excess will be observed in one of the cardinal points. However, at the municipal district level, the distribution is more uniform, with a slight predominance of the northern slopes.

It is known that in the Verkhneuslonsky municipal region, the area of agricultural land is 84.8 thousand ha (65\% of the district), of which 58.6 thousand ha (46\% of the district) are arable [1].

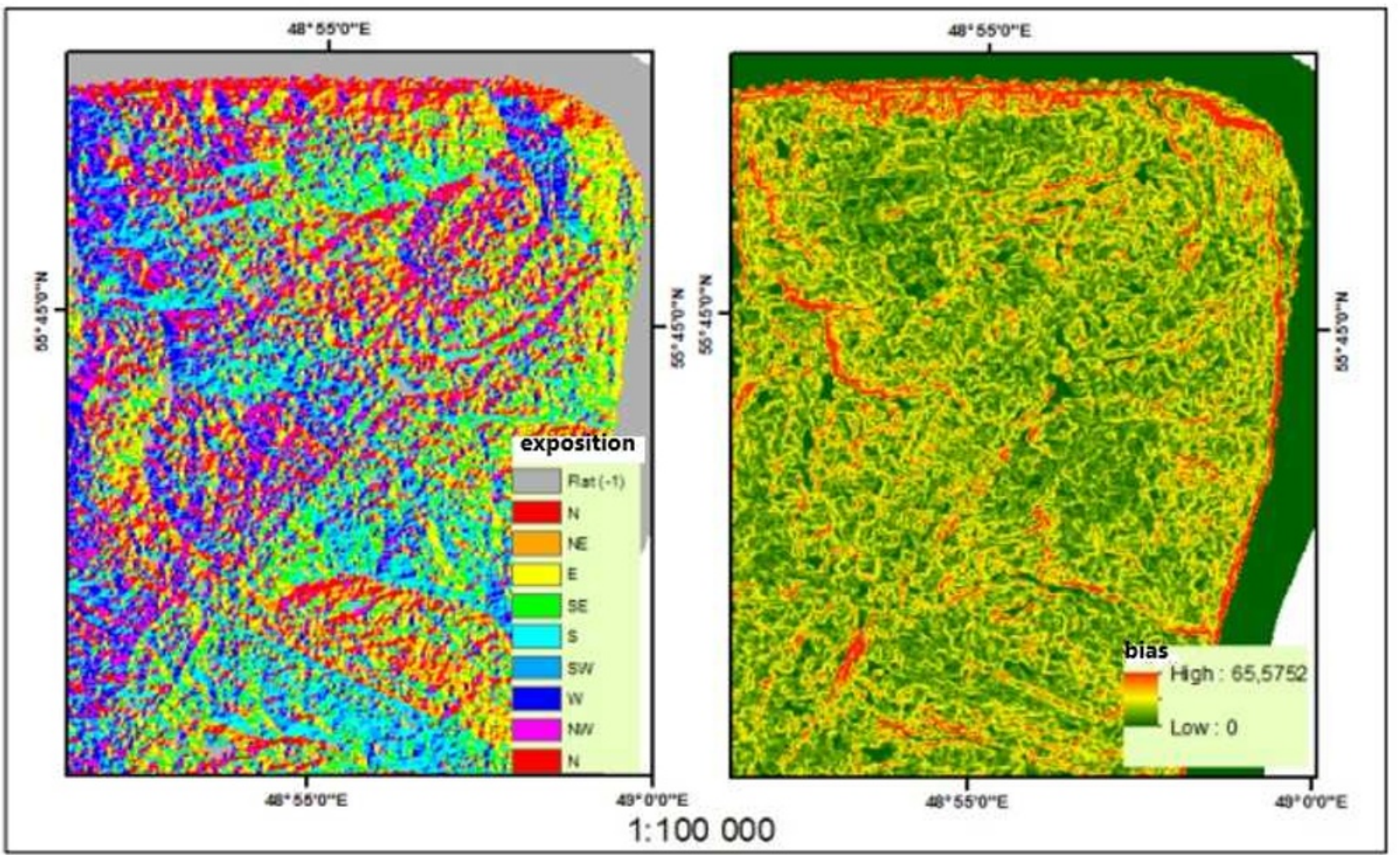

Fig. 2. Expostion map (left) and bias (right)

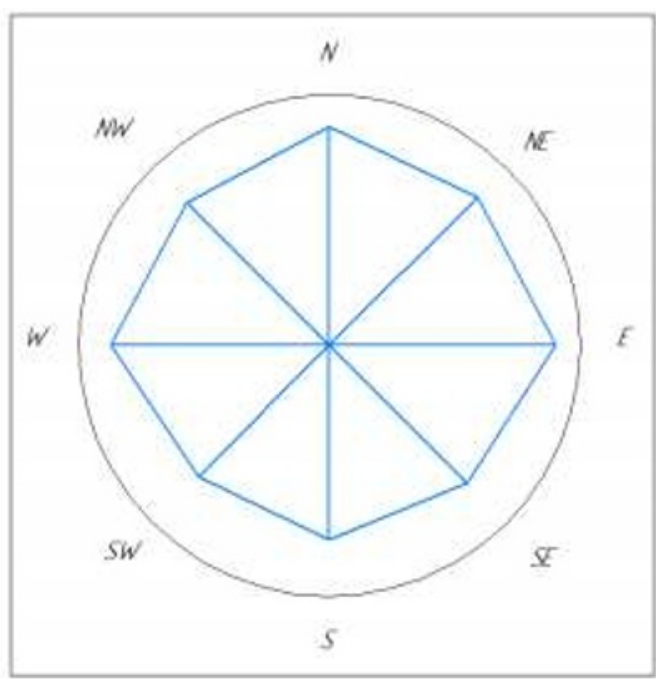

Fig. 3. The distribution of the exposure of the slopes in the territory of the Verkhneuslonsky municipal region on the main cardinal points.

\section{Results and discussion}

Exposition maps are maps containing information about the probability of a particular phenomenon. A map of the susceptibility of gully erosion to the territory of the
Verkhneuslonsky municipal region was constructed using the DTM ASTER GDEM. In this case, to facilitate the process, the territory of the study area was divided into sheets (Fig. 4), the distance between the points was set to $90 \mathrm{~m}$. In addition, water bodies were excluded.

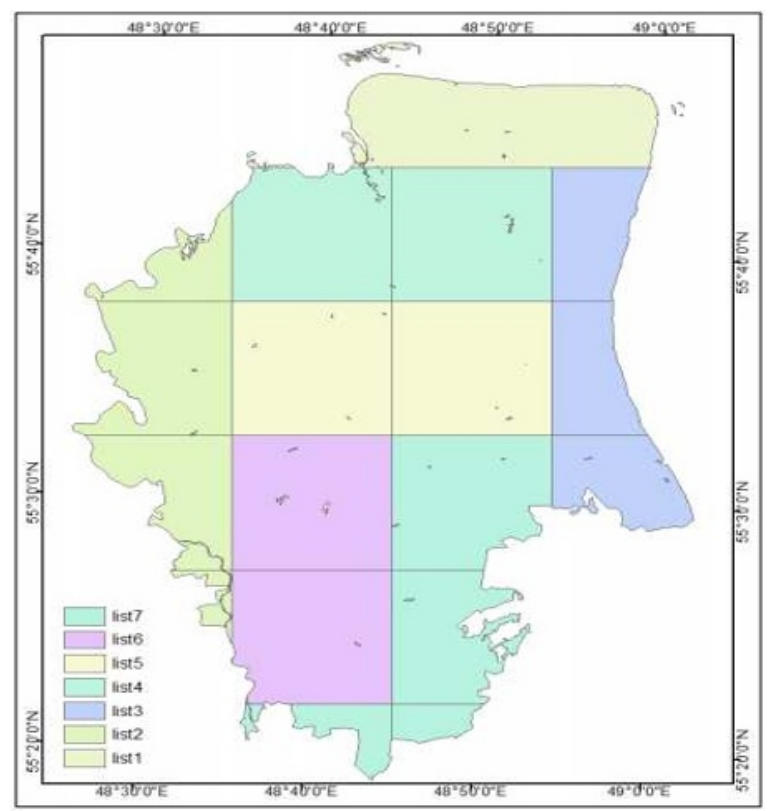

Fig. 4. The layout of the study area 
Then, using the Points to Raster tool in ArcGIS provides a bitmap. In the layer settings, the installation of the desired colour palette is possible. Combining sheets is possible using the Mosaic tool [5, 8]. Thus, it was possible to obtain a map of the susceptibility (or susceptibility) of the territory to ravine erosion (Fig. 5).

The resulting map shows an indicator of the likelihood of ravine erosion at each point in the picture. Compared to the satellite image, Sentinel-2 (11/11/2018) correctly reflects the ravine distribution model $[9,10]$.

Next, we consider the differences and similarities between the exposure map and the satellite reference image in order to evaluate the accuracy of the data and identify artefacts. In fragment No. 1 (Fig. 6), the ravines are distinguished in contrast to the flat sections dividing the high bank of the Sviyaga on the left and the classic tree-like ravine on the right, their shapes and sizes are close to reality. Artefacts were found for the false determination of ravines in the wooded area and vegetation of floodplains, while the false determination of places without ravine erosion was almost not detected.

Fragment No. 2 (Fig. 7) reflects a dense network of ravines in which the entire ravine network has a tree-like shape. At the junction of ravines with maternal ravines, there is a high probability of ravine erosion. As artefacts, the same thing happens as, in the first example, places without erosion of the ravine are determined correctly.

The following fragments No. 3 and No. 4 (Fig. 8, Fig. 9) show the largest artefacts in the area - the forest masses through which a network of ravines passes.
However, flat areas not occupied by forest are precisely defined.

Based on a detailed review of the map, it is possible to conclude that, excluding forest vegetation, a real picture of the distribution of the ravine network throughout the study area can be seen.

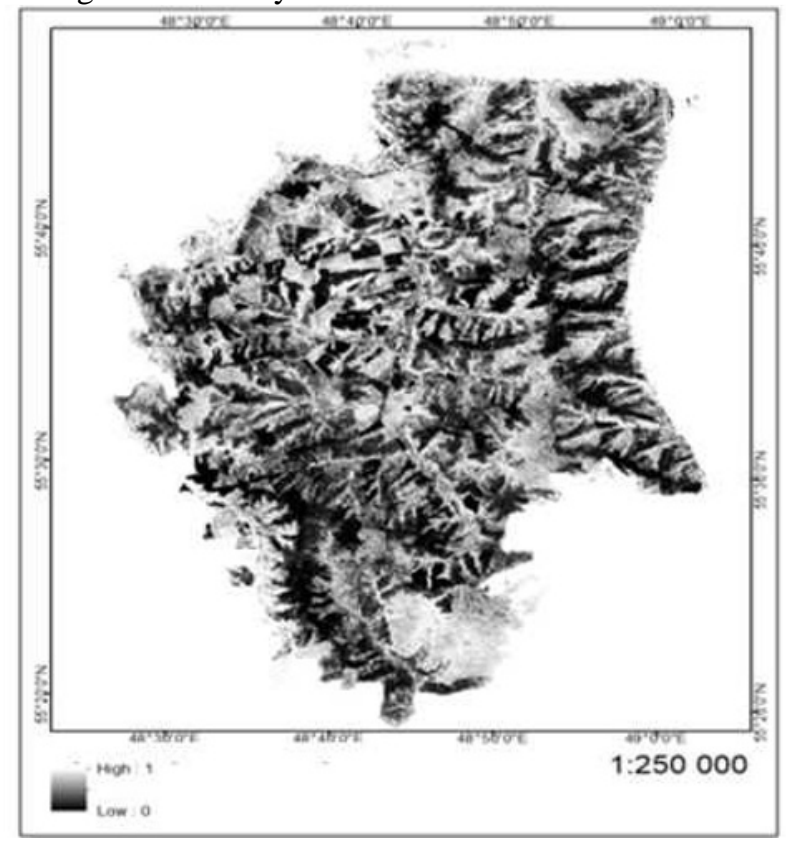

Fig. 5. The territory of the Verkhneuslonsky municipal district, subject to ravine erosion

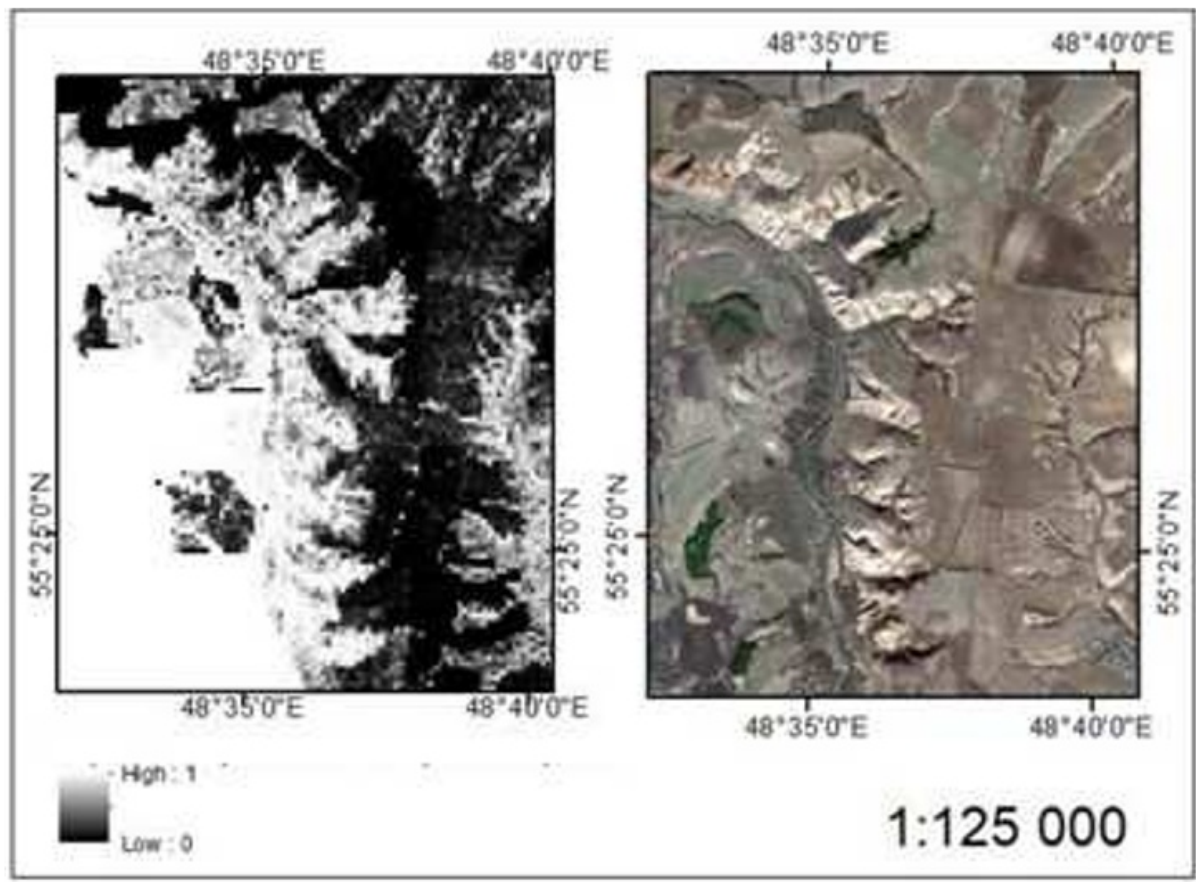

Fig. 6. Map of the exposure of the area of ravine erosion (fragment No. 1) 


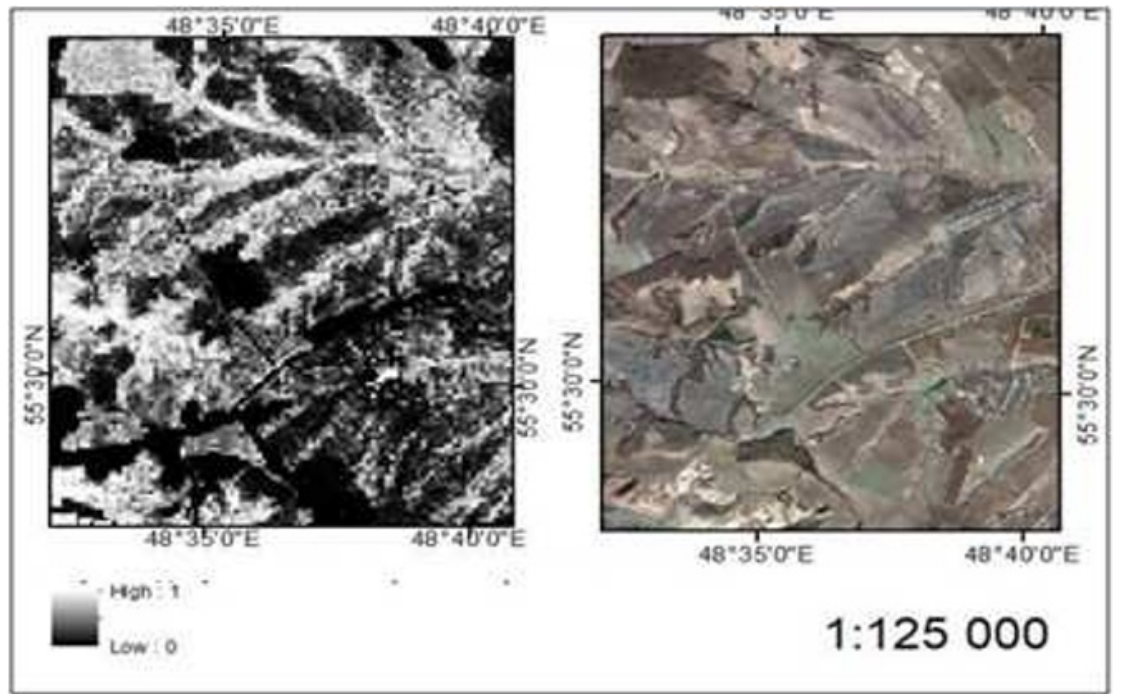

Fig. 7. Map of the exposure of the ravine erosion area (fragment No. 2)

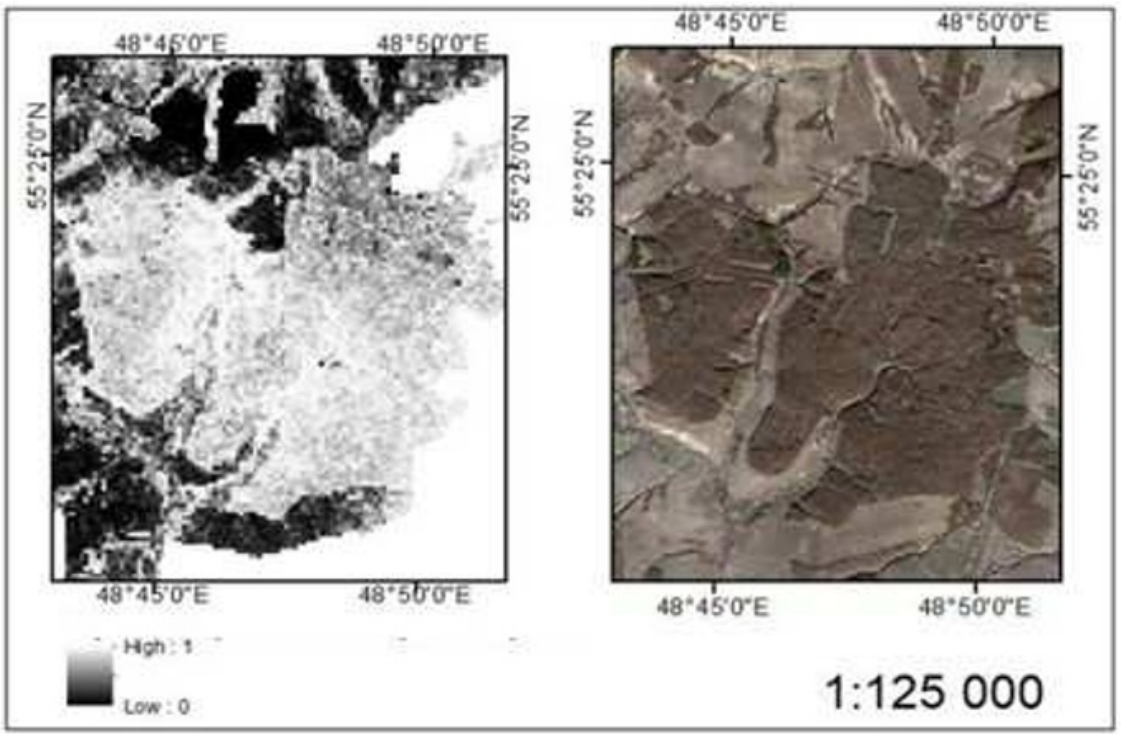

Fig. 8. Map of exposure to the area of ravine erosion (fragment No. 3)

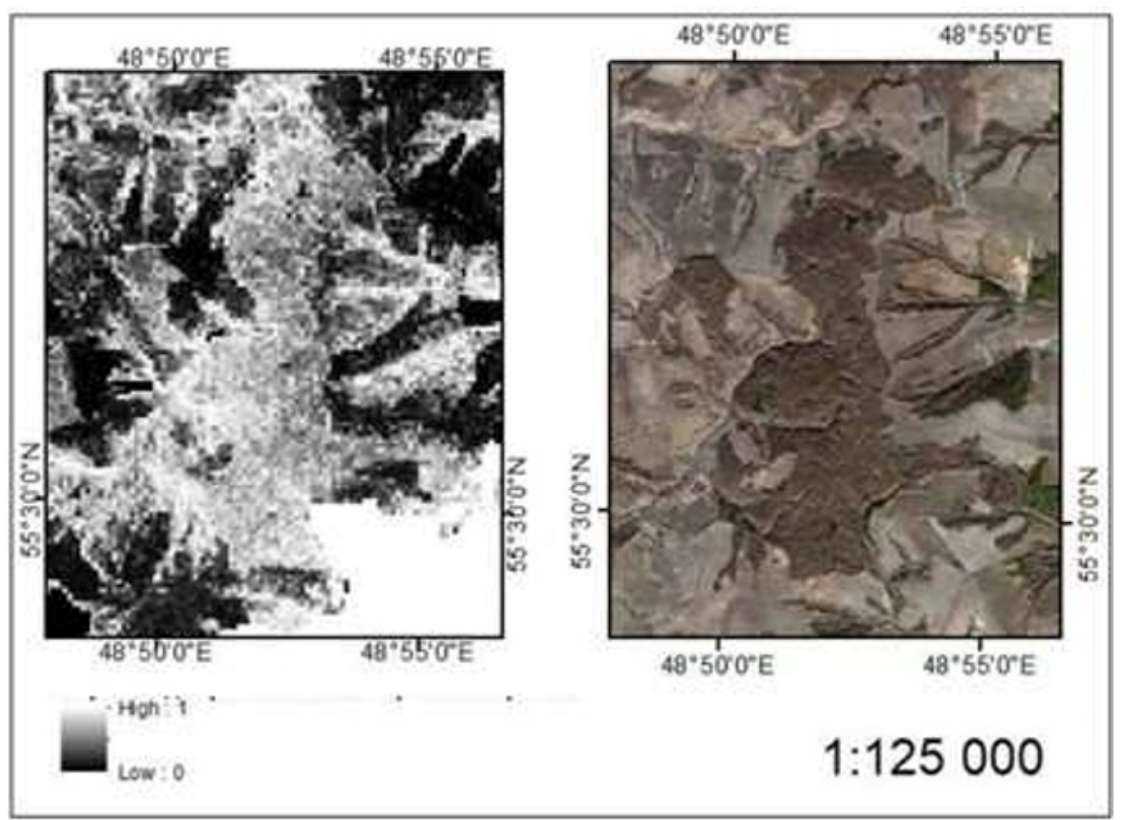

Fig. 9. Map of the exposure of the ravine erosion area (fragment No. 4) 
The effect of false detection of ravine erosion in places of forest vegetation is due to the increased influence of NDVI on the constructed model of logistic regression. However, the risk of ravine erosion in forests is not as relevant as in open areas so that these artefacts can be excluded.

\section{Conclusion}

Studying the factors of ravine erosion allows understanding its essence as a phenomenon in the abiotic part of the landscape. So, it was found that NDVI, reflecting the state of the vegetation cover, surface slope, absolute height and distance to roads, are the most significant factors in the formation of erosion. The northeastern exposition showed great importance in a series of eight main expositions. The planned curvature turned out to be a more significant factor than the profile one. In this work, GIS technologies are of paramount importance in the preparation, processing and visualization of data, as well as in the studied phenomenon as a whole. Earth remote sensing data and their product, such as the global DEM, contain much different information about the object of study, so they also played a vital role in this study.

\section{References}

1. R.A. Gayfutdinova, O.P. Ermolaev, Factors and Spatio-temporal features of the development of ravines in the Republic of Tatarstan, Bull. of the Udmurt Univer. Ser. Biol. Earth sci., 2, 132-141 (2016)

2. M.A. Ivanov, K.A. Maltsev, Assessment of land-use dynamics in river basins of the European territory of Russia according to Landsat, in: Erosion, channel and wellhead processes (research by young scientists from universities), A coll. of art. based on the mater. of the XI sem. of young sci. of universities, united by the Interuniver. Sci.
Coordinat. Council on the probl. of erosion, channel and wellhead proc. (Minin Univer., N. Novgorod, 2016) pp. 117-124

3. I.I. Mazur, O.P. Ivanov, Hazardous natural processes, Textbook (Publ. House "Economics", Moscow, 2014) 702 p.

4. A.M. Sabirzyanov, N.A. Loginov, A.M. Sharafieva, Using remote sensing data to study slope processes on the territory of the Pechishchinsky geological section natural monument, Achievem. of sci. and technol. of the agro-indust. Complex, 33(8), 10-13 (2019)

5. R.A. Medvedeva, O.P. Ermolaev, Using the methods of remote sensing of the Earth to study the Spatiotemporal changes of the ravine network, In: V.N. Golosova, O.P. Ermolaeva (eds.), Spatial-temporal patterns of development of modern processes of natural and anthropogenic erosion on the Russian Plain (Publ. House of the Acad. of Sci. of the Repub. of Tajikistan, Kazan, 2019) pp. 58-67

6. O.P. Ermolaev, R.A. Medvedeva, E.V. Platoncheva, Methodological approaches to monitoring erosion processes on agricultural lands of the European part of Russia using satellite imagery materials, Sci. notes of Kazan Univer. Ser. of natural sci., 159(1), 668-680 (2017)

7. R.A. Medvedeva, Trends of the gully erosion development in the territory of the Republic of Tatarstan, IOP Conf. Ser. Earth and Environ. Sci., 107(1), 012016 (2018)

8. R.A. Schauvenerdt, Remote sensing. Models and methods of image processing (Technosphere, Moscow, 2010) $516 \mathrm{p}$.

9. V.N. Gubin, Remote methods in geology, Lecture course (BSU, Minsk, 2014) 138 p.

10. V.M. Eliseev, O.V. Gavrilova, The formation of spatially-linked local GIS for mapping purposes: a training manual (RUDN, Moscow, 2018) 162 p. 